\title{
A Modified Sequential Regimen of Helicobacter pylori Treatment Enforced by Bacillus clausii and Zinc Carnosine Complex Yields High Eradication Rates
}

\author{
Dajani AI*, Nounou MA, Fayadh MH, Sabih SA, Kassim L and Abu Hammour A \\ Gastroenterology Division, Emirates Medical Association, UAE
}

Submission: April 26, 2017; Published: May 15, 2017

${ }^{*}$ Corresponding author: Dajani AI, Gastroenterology Division, Emirates Medical Association, Pan Arab Association of Gastroenterology, Sharjah, Dubai, UAE, Email: aidajani@emirates.net.ae

\begin{abstract}
Introduction: Over the past decade a worldwide trend of decline in the cure rates of Helicobacter pylori is observed. Current eradication rates achieved by the standard triple therapy are below $70 \%$. Sequential therapy had provided a potential alternative that would compensate for the unmet performance of triple therapy. Despite its superiority to triple therapy, the excellent results reported initially were not reproduced by other investigators work. Adding adjuvant agents was also found to improve further the success rate of eradication. Probiotics emerged as a useful adjunct in treatment and prophylaxis of Helicobacter pylori infection. The nutritional supplement Zinc carnosine complex is another adjuvant which is believed to add value to the treatment.
\end{abstract}

Patients and method: an open label randomized observational clinical study designed to compare the efficacy of a modified sequential regimen enforced by two adjuvants the probiotic Bacillus clausii and the nutritional Zinc Carnosine supplement. Patients who fulfilled the inclusion and exclusion criteria were randomized to one of two groups who were given the same components of the regimen of treatment either with clarithromycin (group A, $\mathrm{n}=131$ ) or levofloxacin replacing it (group B, n=137) and were compared against the current reported response to triple therapy in our area (67.9\%).

Results: This regimen of eradication had yielded a Per protocol cure rate of $96.4 \%$ and an ITT rate of $89.9 \%$ for the levofloxacin based therapy. The Per protocol eradication rate for the clarithromycin based treatments was $93.4 \%$ and the ITT rate was $90 \%$. The response was not significantly affected by previous exposure to the antibiotics used. Patient satisfaction and compliance were remarkable with most patients having a significant feeling of wellbeing and improvement of their symptoms. Side effects to the components of the regimen were unremarkable. The addition of Bacillus clausii and the nutritional supplement Zinc Carnosine had added great value to the eradication response.

Keywords: H. pylori; Bacillus clausii; Carnosine; Sequential therapy

\section{Introduction}

Helicobacter pylorimay impose significant deleterious effects on the stomach, being the most common cause of gastritis, gastric and duodenal ulcers, MALT lymphomaand gastric malignancy, this makes eradication of this infection of prime importance to health care professionals $[1,2]$. The eradication response by the triple therapy, used to achieve a success rate over $90 \%$ in the early nineties but had declined to less than $70 \%$ currently which had raised concerns about cure of this infection and evoked the interest amongst researchers to develop more effective and reliable regimens of treatment [3-6]. The observed failure of eradication by the triple therapy appears to be related mainly to resistance to the antibiotics clarithromycin and metronidazole. Non-compliance, caused by the side effects of the drugs that are used and reinfection are also other contributory factors. Several methods were recommended to overcome the decline in the outcome of triple therapy. Modifying the triple therapy by changing clarithromycin with levofloxacin was associated with a considerable improvement in Helicobacter pylori eradication [7,8]. The sequential regimen of therapy and the addition of adjuvant agents to enforce the response to antibioticshave also emerged as other alternative ways that had gained wide acceptance lately.

Sequential therapy, is an innovative non-bismuth based quadruple strategy consisting of a 10-days treatment course which involves a proton pump inhibitor (PPI), Amoxicillin, Clarithromycin 
and Metronidazole given in sequence rather than simultaneously. It was first introduced by Vaira et al. [9,10]. Early reports indicated that the sequential therapy had led to $95 \%$ eradication which was significantly superior to eradication rates achieved with the standard triple therapy [9]. Ten days of treatment were considered sufficient as extension of treatment to 14 days did not lead to any significant benefit and yielded almost the same results when this regimen is used [10]. The gastric pathology induced by the bacteria also did not seem to affect the outcome of sequential therapy as ulcer patients and patients with non-ulcer dyspepsia had similar cure rates [11]. Risk factors known to facilitate failure of eradication like the absence of the Cag A gene or smoking, does not have any impact on cure with this regimen [12]. Clarithromycin resistance that contributed to the reduced response by the triple therapy, was far less observed when the medicines were given sequentially indicating that the sequential regimen of therapy would be expected to reduce markedly the impact of clarithromycin resistance on eradication [13].

Other approaches towards the improvement of eradication of Helicobacter pylori was suggested by the addition of adjuvant agents that aim at supporting the different antibiotic regimens, improving their outcome and minimizing or preventing any possible adverse events. Bovine lactoferrin, probiotics and Carnosine zinc gained considerable interest in this respect as adjuvants to Helicobacter pylori eradication by many researchers. It is believed that Bovine lactoferrin (bLf) has bacteriostatic and bactericidal properties against various infectious agents due to its ability to bind iron with great affinity, thus preventing iron utilization by Helicobacter pylori and consequently its growth [14]. Several human, randomizedcontrolled trials (RCTs) however, had reported limited or equivocal benefit with some authors reporting acceptable efficacy and others lack of it.

The mucosal protective agent, Zinc-carnosine complex is a unique dietary supplement that provides targeted support for stomach health, and relieves a number of symptoms associated with indigestion. Zinc-carnosine, contributes to ulcer healing through a number of different mechanisms, including inhibition of Helicobacter pylori, promotion of wound healing, antioxidant effects, and stimulation of gastric mucus secretion. The zinc component, may inhibit $\mathrm{H}$ pylori-induced $\mathrm{PMN}$-mediated gastric inflammation by attenuating CD11b/CD18 expression on PMN and IL-8 production from gastric epithelial cells and down-regulating other inflammatory cytokines. Carnosine zinc had been used as adjunctive therapy in combination with conventional ulcer drugs $[15,16]$.

Literature supporting the activity of probiotics in eradication of Helicobacter pylori infection had shown that lactobacilli may inhibit or kill Helicobacter pylori, prevent its adhesion to mammalian epithelial cells and prevent IL8 release [17]. In vitro cell line experiments, testing L. rhamnosus strains, Propionibacterium freudenreichii subspecies and Propionibacterium shermanii, had demonstrated that probiotics decreased the level of Helicobacter pylori adhesion to intestinal epithelial cells, inhibited Helicobacter pylori-induced acute membrane leakage and improved transiently the epithelial barrier function [18]. A meta-analysis of 14 randomized clinical trials evaluating the role of supplemental probiotics in eradication therapy had demonstrated an increase in cure rates from $74.8 \%$ to $83.6 \%$. The analysis revealed that the combined treatment, not only had increased the eradication rate, but had also decreased the occurrence of adverse events due to the antibiotics, such as diarrhea [19]. We reported a significant benefit of adding the probiotic Bifidobacterium infantis as an adjuvant to both the standard triple and sequential therapy when taken concurrently at the same time, or after priming the GI tract for 2 weeks. A successful eradication rate of $83 \%, 90.5 \%$, and $90.8 \%$ was obtained respectively. Each was significantly better than triple therapy alone $(68.9 \%, \mathrm{P}<0.001)$ [20].

Bacillus clausii is classified as a probiotic, it is a rod-shaped, Gram-positive, motile and spore-forming bacterium belonging to the fermicutes group, which lives in the soil. Bacillus clausii contributes to the recovery of the intestinal microbial flora altered during the course of microbial disorders of diverse origin. The beneficial clinical effects that it exerts can at least be partially the result of the antimicrobial and immunomodulatory activities of its different strains on the various parts of the digestive system [21]. Clinical trials have also examined the positive impact of Bacillus clausii on the side effects of antibiotic-based Helicobacter pylori therapy and concluded that it reduced the incidence of the most common side-effects related to anti-Helicobacter pylori antibiotic therapy compared with placebo [22].

Many other in-vivo and in-vitro studies confirmed the same expectancies with other probiotics, like Bifidobacterium infantis [19], Saccharomyces boulardii [23] and Lactobacillus gasseri which when used along with standard triple therapy was found to be effective in both suppressing Helicobacter pylori and reducing mucosal inflammation particularly in the clarithromycin resistant patients, thus increasing the eradication rates and decreasing overall therapy-related side effects [24].

Despite the growing knowledge about the use of probiotics as adjuvants to the different therapeutic regimens of Helicobacter pylori there is still lack of standardization in terms of the type of the probiotic strain to be used, whether it would be a single strain or multispecies strains, the dosage and the timing of supplementation.

We hereby are describing a modified sequential regimen of therapy which is based on the sequential protocol of treatment but with extending the use of amoxicillin to the whole duration of therapy (10 days) and enforcing the outcome by adding two adjuvant agents, the probiotic Bacillus clausii and the dietary supplement Zinc Carnosine, with a view to improve on the failing eradication response obtained by the standard triple therapy alone. This regimen was applied in two versions one was clarithromycin based and the other was levofloxacin based. 


\section{Patients \& Methods}

A prospective randomized open label clinical study was designed to evaluate the efficacy of a hybrid sequential therapy fortified by two adjuvant agents in improving eradication rates of Helicobacter pylori infection. Patients were randomly assigned to two groups basically with the same medications but one (group A) with clarithromycin used in the 5 days of quadruple phase of treatment and the other (group B) with levofloxacin replacing it. The adjuvants used were the probiotic Bacillus clausii and the dietary supplement Zinc-carnosine both added concomitantly to the eradication regimen for the whole 10 days.

Primary end point: evaluation of the intention to treat (ITT) and the per protocol (PP) cure rates of Helicobacter pylori for each group of patients at least six weeks after finishing treatment. Secondary end point: evaluation of the clinical response and the incidence of adverse effects to the antibiotics used.

\section{Inclusion criteria}

All consenting patients, 12-70 years of age who presented with upper gastrointestinal symptoms, and appeared to have Helicobacter pylori infection as concluded by endoscopy, 13C Urea breath test or by detecting the pylori antigen in stool or by more than one method of those when done. All patients however, had a base line 13C Urea breath test, at enrolment regardless of the method of diagnosis if it was otherwise.

\section{Exclusion criteria}

The presence of any concomitant illness that might have an impact on the response to the used medicines. These included, patients known to be allergic to any of the medicines used, patients who would develop adverse reactions after starting therapy, use of other medications that might interact with the prescribed medicines, chronic renal or hepatic insufficiency, and neoplastic disease. Other criteria taken into consideration were pregnancy or lactating mothers as a standard exclusion, non-consenting patients, patients who were diagnosed and treated on the basis of the office serology test for Helicobacter pylori alone and patients who had received clarithromycin for any clinical indication within the six months that preceded enrolment.

The study extended over a period of a year time, in four medical centers. Data for each group were analyzed as per patient's treatment status whether they were naïve, or they had a failed previous attempt of eradication at least 6months prior to enrolment. Each patient should have a follow up visit at 6-8 weeks after completing the treatment where clinical evaluation and a $13 \mathrm{C}$ Urea breath test were done to document response to treatment.

\section{Method}

a) Group A: a cohort of 131 patients who received treatment in two phases, phase I included Lansoprazole $30 \mathrm{mg}$, Amoxicillin $1000 \mathrm{mg}$, Bacillus clausii 2 thousand million in rigid capsule, and Zn-carnosine $75 \mathrm{mg}$ all given twice daily for 5 days, followed by phase II which included the same medicines, but with the addition of Clarithromycin 500mg, and Tinidazole 500mg and all were given twice daily for the subsequent 5 days. Demographic details for this group are included in Table 1.

Table 1: Matchable demographic details for both groups.

\begin{tabular}{|c|c|c|}
\hline & $\begin{array}{c}\text { Group A } \\
\text { “Clarithromycin based" }\end{array}$ & $\begin{array}{c}\text { Group B } \\
\text { “Levofloxacin based }\end{array}$ \\
\hline \multicolumn{3}{|c|}{ Number } \\
\hline Total & 131 & 137 \\
\hline Treatment Naieve & $75(56.3 \%)$ & $78(56.9 \%)$ \\
\hline Retreat & $54(43.7 \%)$ & $59(43.1 \%)$ \\
\hline Mean Age & $44.4(14-67)$ & $43.9(16-65)$ \\
\hline Gender M:F & $68: 63(1: 1.07)$ & $71: 66(1: 1.08)$ \\
\hline Mean BMI & $28.4(21-39)$ & $27.9(22-38)$ \\
\hline \multicolumn{3}{|c|}{ Ethnicity } \\
\hline Arab & $38(29.01 \%)$ & $42(30.66 \%)$ \\
\hline Asian & $41(31.30 \%)$ & $37(27.01 \%)$ \\
\hline European & $21(16.03 \%)$ & $20(14.60 \%)$ \\
\hline African & $31(23.66 \%)$ & $38(27.73 \%)$ \\
\hline
\end{tabular}

b) Group B: A cohort of 137 patients. They received treatment also in two phases, phase I same as in group A which included Lansoprazole $30 \mathrm{mg}$, Amoxicillin $1000 \mathrm{mg}$, Bacillus clausii 2 thousand million in rigid capsule, and $\mathrm{Zn}$-carnosine $75 \mathrm{mg}$ all given twice daily for the first 5 days, followed by phase II which included the same medicines, but with the addition of levofloxacin $500 \mathrm{mg}$, and Tinidazole $500 \mathrm{mg}$ and all were given twice daily for the subsequent 5 days. Demographic details for this group are included in Table 1. Results of eradication for each patient were tested at a follow up visit 6-8 weeks after completing the treatment where clinical evaluation and a $13 \mathrm{C}$ Urea breath test were done to document response.

The overall eradication rates and their $95 \%$ confidence intervals were obtained by per protocol and intention-to-treat analysis. Quantitative variables were given as means \pm SD. A univariate analysis including age, sex, body mass index, ethnicity, smoking habit (active smoker vs non-smoker), baseline disease (organic vs functional), was performed. Variables achieving a P-value lower than 0.3 were included in a multivariate analysis performed by logistic regression. P-values lower than 0.05 were considered significant. Calculations were performed using the IBM SPSS 20.0 software.

\section{Results}

a) Group A: Seventy-five patients (57.3\%) in this group were naïve to eradication treatment, while 54 patients (43.7\%) were treated before with clarithromycin based triple therapy but had failed to respond. The Per protocol (PP) cure rate for the whole cohort was $93.4 \%$. Analysis on an intention to-treat basis (ITT) indicated a rate of $90.8 \%$, almost similar to the PP results. The PP cure rate for naïve patients in this group was $93.3 \%$ and for the experienced patient was $90.0 \%$ with no statistical difference 
$\mathrm{p}=0.447$. The ITT cure rate was $93.1 \%$ for the naïve patients whereas the experienced patients had an ITT cure rate of $87.5 \%$, with no remarkable difference $\mathrm{p}=0.228$ (Figure $1 \& 2$ ).

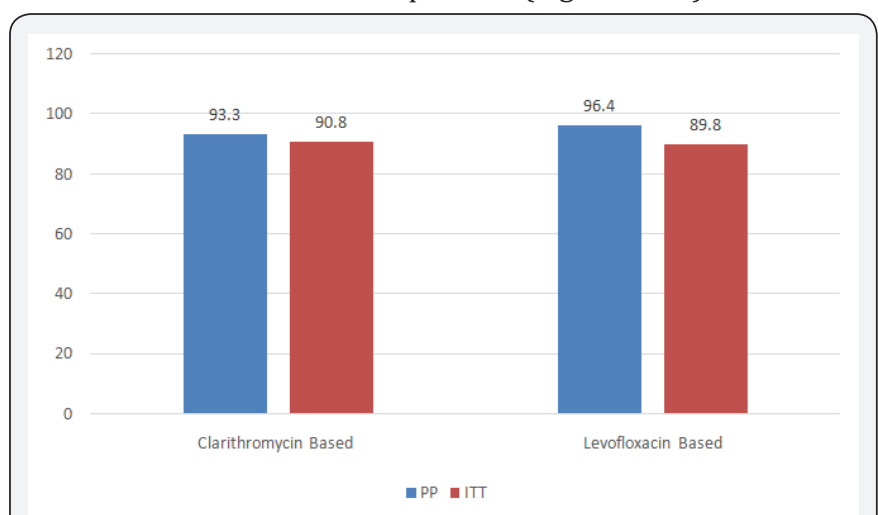

Figure 1: PP \& ITT eradication group for the whole cohort.

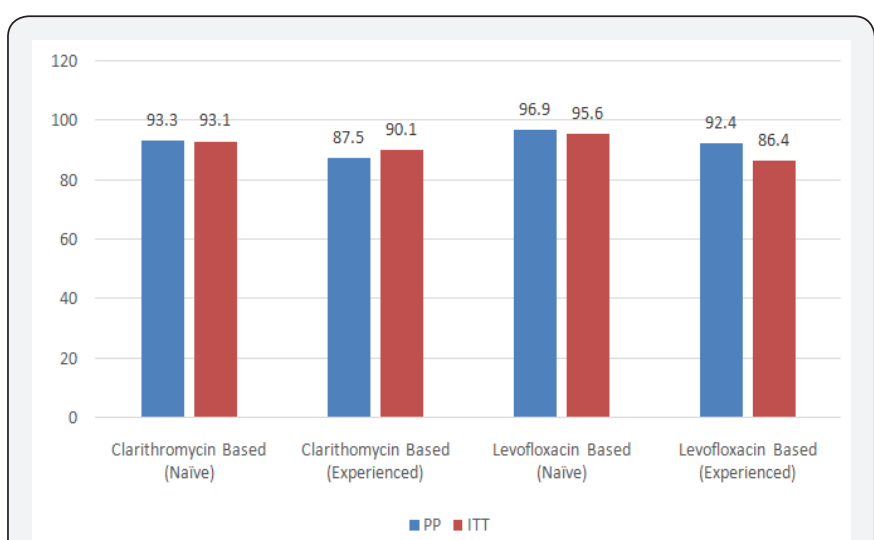

Figure 2: For both groups as per treatment status: Naïve or experienced.

The demographic details (age, gender, body mass index, and ethnicity) for this group did not appear to have any bearing on the response to this regimen of eradication. There was no statistical difference of eradication rate amongst subgroups of these parameters as shown in Table 2. Patients' overall evaluation of the subjective symptoms expressed as mild, moderate or severe, before and after treatment is summarized in Table 3, and indicate that patients were extremely satisfied by the treatment with their symptoms disappearing in 119 patients $(90.8 \%)$ of the cohort at the end of treatment $(\mathrm{p}<0.0001)$. Review of the bowel habits revealed that 94 patients $(71.8 \%)$ had normal bowel habits at the end of treatment with significant reduction in the number of patients who suffered from loose bowel motions (Table 3, p=0.0001).

b) Group B: Seventy-eight patients (56.9\%) in this group were naïve to eradication treatment, while 59 patients (43.1\%) were treated before with clarithromycin based triple therapy but failed to respond. The PP cure rate for the whole cohort was $96.4 \%$ and the ITT rate was $89.8 \%$. The PP cure rate for naïve patients in this group was $96.9 \%$ and for the experienced patients was $95.6 \%$ with no statistical difference between the two sets of patients $\mathrm{p}=0.470$. The ITT analysis indicated a rate of $92.4 \%$ for naïve patients and a cure rate of $86.4 \%$ for the retreat patient $(\mathrm{p}=0.175)$ (Figure $1 \& 2)$.

There was no impact on the eradication rate by any of the demographic parameters or its subgroups (age, gender, ethnic group and body built) the minor differences noted were not statistically significant, and indicated that the response to eradication treatment was not affected by age, gender, body built or ethnicity Table 2 .

Table 2: Eradication rate as per demographic parameters and their subsets indicating that there is no statistical difference of eradication within the subsets of the same parameters or across with the other group.

\begin{tabular}{|c|c|c|c|}
\hline & $\begin{array}{c}\text { Group A } \\
\text { "Clarithromycin } \\
\text { based" }\end{array}$ & $\begin{array}{c}\text { Group B } \\
\text { “Levofloxacin } \\
\text { based }\end{array}$ & \\
\hline \multicolumn{4}{|c|}{ Age } \\
\hline $\begin{array}{c}12-30 \\
31-50 \\
>50\end{array}$ & $\begin{array}{c}37 / 41(90.2 \%) \\
51 / 56(91.1 \%) \\
31 / 34(91.2 \%) \\
P=0.987\end{array}$ & $\begin{array}{c}28 / 31(90.3 \%) \\
62 / 69(89.9 \%) \\
32 / 37(89.2 \%) \\
P=0.841\end{array}$ & $\begin{array}{l}P=0.991 \\
P=0.818 \\
P=0.532\end{array}$ \\
\hline \multicolumn{4}{|c|}{ Gender } \\
\hline $\begin{array}{l}\text { Males } \\
\text { Females }\end{array}$ & $\begin{array}{c}62 / 68(91.2 \%) \\
57 / 63(90.5 \%) \\
P=0.890\end{array}$ & $\begin{array}{c}63 / 71(88.7 \%) \\
60 / 66(90.9 \%) \\
P=0.933\end{array}$ & $\begin{array}{l}\mathrm{P}=0.632 \\
\mathrm{P}=0.933\end{array}$ \\
\hline \multicolumn{4}{|c|}{ BMI } \\
\hline $\begin{array}{c}<26 \\
26-35 \\
>35\end{array}$ & $\begin{array}{c}29 / 32(90.6 \%) \\
47 / 51(92.2 \%) \\
43 / 48(89.6 \%) \\
P=0.905\end{array}$ & $\begin{array}{c}30 / 33(90.9 \%) \\
51 / 57(89.5 \%) \\
42 / 47(89.4 \%) \\
P=0.971\end{array}$ & $\begin{array}{l}\mathrm{P}=0.968 \\
\mathrm{P}=0.631 \\
\mathrm{P}=0.972\end{array}$ \\
\hline \multicolumn{4}{|c|}{ Ethnicity } \\
\hline $\begin{array}{c}\text { Arab } \\
\text { Asian } \\
\text { European } \\
\text { African }\end{array}$ & $\begin{array}{c}35 / 38(92.1 \%) \\
37 / 41(90.2 \%) \\
19 / 21(90.5 \%) \\
28 / 31(90.3 \%) \\
P=0.991\end{array}$ & $\begin{array}{c}38 / 42(90.5 \%) \\
33 / 37(89.2 \%) \\
18 / 20(90.0 \%) \\
34 / 38(89.5 \%) \\
P=0.998\end{array}$ & $\begin{array}{l}P=0.797 \\
P=0.878 \\
P=0.959 \\
P=0.908\end{array}$ \\
\hline
\end{tabular}

Patients' evaluation of the severity of symptoms (mild, moderate or severe), before and after treatment is summarized in Table 3. One hundred and twenty-two, patients were well satisfied by the treatment with 122 patients (89.1\%) of the cohort reporting disappearance of symptoms by the end of treatment $(\mathrm{p}<0.0001)$. Review of the bowel habits revealed that 102 patients (74.5\%) had normal bowel habits at the end of treatment with significant reduction in the number of patients who suffered from loose bowel motions before treatment was given (Table $3, \mathrm{p}=0.0001$ ). Some patients who had constipation at the start of treatment had an appreciable change in their habits but this was not statistically significant $(\mathrm{p}=0.117)$ 


\section{Advanced Research in Gastroenterology \& Hepatology}

Table 3: Clinical symptoms and bowel habits before and after treatment within the two groups indicating a significant improvement in all parameters.

\begin{tabular}{|c|c|c|c|c|c|c|}
\hline & \multicolumn{3}{|c|}{$\begin{array}{c}\text { Group A } \\
\text { “Clarithromycin based” }\end{array}$} \\
\hline & Before & After & P value & Before & Group B \\
“Levofloxacin based
\end{tabular}

\section{Discussion}

Helicobacter pylori is the most common cause of gastrointestinal infections. It is indigenous to humans and infects at least $70-80 \%$ of people in developing countries and $30-40 \%$ of people in Western nations [25,26]. The incidence of Helicobacter pylori infection is declining significantly in Western nations [27] but it is relatively stable or is slightly decreasing in the developing countries.

Infection usually takes place in early childhood and spreads by direct human-human transmission within close family members [28]. Without treatment, it persists for a lifetime. The majority of individuals who acquire Helicobacter pylori do not develop acute symptomatology, although chronic, diffuse superficial gastritis commonly occurs. Chronic infection with Helicobacter pylori is the primary cause of peptic and gastric ulcerations, distal gastric adenocarcinoma, and gastric MALT lymphoma $[29,30]$.

Most guidelines recommend treating Helicobacter pylori by the standard triple therapy (A twice daily dose of a proton pump inhibitor, Amoxicillin $1000 \mathrm{mg}$, and clarithromycin $500 \mathrm{mg}$ or metronidazole $500 \mathrm{mg}$ ) for 7-10 days which was satisfactorily successful, in the early days of Helicobacter pylori treatment yielding an eradication rate of 95-96\% [3-6]. Lately, however, several reports had indicated a decline in the eradication rate of Helicobacter pylori with this regimen of therapy [31]. This had alarmed researchers to explore alternative ways of treatment either by changing the antibiotic, or by adopting other protocols of therapy, or by adding adjuvants that may help enhance the response to the standard treatment like probiotics, lactoferrin, plaunotol and zinc carnosine.

The modified sequential regimen that we adopted as an eradication therapy had led to an excellent per protocol eradication rates of $96.4 \%$ and $93.3 \%$ for the levofloxacin based and the clarithromycin based regimens respectively. This was significantly better than the eradication rate obtained from the standard triple therapy $66.9 \%$ [46], $\mathrm{p}=<0.0001$. Although the Levofloxacin based treatment was apparently slightly better, yet there was no statistical difference when compared with the clarithromycin based regimen $(p=0.308)$. We believe that the outstanding response to this regimen is attributed to the components of this therapeutic protocol namely the antibiotics and the adjuvants.

The antibiotics used for eradication included amoxicillin, clarithromycin, levofloxacin and tinidazole.

I. Amoxicillin: amoxicillin is a standard medicine used in all eradication regimens except where there is sensitivity to the penicillins and it is generally viewed that there is no resistance to this antibiotic. Rare tolerance to amoxicillin however, has also been described and was attributed to alterations in penicillin binding proteins (PBP1A) [32].

II. Clarithromycin: Clarithromycin resistance appears to be on the rise worldwide. Analysis of DNA sequencing had revealed several factors contributing to this resistance of which mutations at position 2142 (A-to-G transition) and position 2182 (C-to-T transition) have been confirmed [33]. An active drug efflux mechanism responsible for rapidly transferring the drug out of the bacterial cell, preventing the binding of the antibiotic to the ribosome, plays an important role in acquiring clarithromycin resistance [34,35]. In UAE Primary clarithromycin resistance is $24 \%$ and secondary resistance is 55\% (Abu Hammour et al EDDW 2015)

III. Levofloxacin: Levofloxacin-based regimens for the initial retreatment of Helicobacter pylori infection have shown primarily positive results, with eradication rates between 57\% and 91\% [3638]. A met analysis indicated that there was no significant difference noted between regimens of $250 \mathrm{mg}$ twice daily and $500 \mathrm{mg}$ once daily [39]. Helicobacter pylori resistance to levofloxacin has been associated with prior fluoroquinolone use $(\mathrm{p}<0.001)$ and with the total number of fluoroquinolone courses prescribed [40].

IV. Tinidazole: Tinidazole have some advantages over metronidazole of the same family whichinclude an enhanced activity 
as it is not affected by gastric $\mathrm{pH}$, favorable pharmacokinetics, and increased tolerability. Multiple clinical trials demonstrated the effectiveness of a tinidazole-based regimen (plus clarithromycin and a PPI) as first-line therapy for Helicobacter pylori infection. A randomized, blinded study found that a tinidazole-based regimen resulted in an eradication rate of more than $90 \%$ in metronidazolesusceptible strains and $75 \%$ in low-level metronidazole-resistant strains (minimum inhibitory concentration [MIC] 4256mg/L) [41].

V. Adjuvant therapy: The most potent adjuvant therapy consists of increasing the stomach $\mathrm{pH}$ with proton pump inhibitors (PPIs). In addition to this action on stomach pH, PPIs, and especially lansoprazole, have been found to have antimicrobial activity against Helicobacter pylori. Anti-Helicobacter pylori activity has been reported for non-traditional antimicrobials such as proton pump inhibitors, bismuth compounds, mucosal defensive agents, and some other agents. Proton pump inhibitors and their acidactivated derivatives have significant activities against Helicobacter pylori, potent inhibitors of urease, proton motive force, and ATPase of Helicobacter pylori. At high concentrations, they are even bactericidal. Furthermore, they can inhibit Helicobacter pylori urease activity. These properties, as well as their anti-secretory activity, provide the grounds for their use in eradication of Helicobacter pylori.

The use of probiotics to modify the conventional treatment regimens is based on sound biological and physiological principles. Probiotics modulate the intestinal ecosystem by stimulating mucosal immune mechanisms and by stimulating non-immune mechanisms through antagonism with potential pathogens. These phenomena are thought to mediate most beneficial effects, including reduction of the incidence and severity of diarrhea. Probiotics had an in vitro inhibitory effect on Helicobacter pylori. Seven of 9 human studies showed an improvement of Helicobacter pylori associated gastritis and a decrease in Helicobacter pylori colonization after the administration of probiotics. On the other hand, the addition of probiotics to the standard antibiotic treatment had improved Helicobacter pylori eradication rate from $71 \%$ when given alone to $81 \%$ with combination treatment. In addition, probiotic treatment reduced the antibiotic associated side effects remarkably (incidence of side effects: $23 \%$ with combination therapy vs. $46 \%$, for Helicobacter pylori eradication treatment alone). A recent metaanalysis of 14 randomized trials suggested that supplementation of anti-Helicobacter pylori antibiotic regimens with certain probiotics may also be effective in increasing eradication rates and may be considered helpful for patients with eradication failure [42]. Further clinical studies will be necessary to establish better guidelines in supplementation of anti-Helicobacter pylori antibiotic regimens. There is currently insufficient evidence to support the concept that a probiotic used alone, without concomitant antibiotic therapy, would be effective but it is widely accepted that they may reduce the gastrointestinal side effects of antibiotic therapy and improve patient compliance [43]
It was demonstrated that in symptom free, Helicobacter pylori positive subjects Bacillus clausiibacteriotherapy reduced the incidence of the most common side-effects related to antiHelicobacter pylori antibiotic therapy compared with placebo. They may especially be helpful in patients with recurrent Helicobacter pylori infection and a history of gastrointestinal adverse effects with antibiotics [44, 45]. Mucosal defensive agents that enhance defense factors of gastro-duodenal mucosa are locally acting anti-ulcer drugs. Some were found to have direct or indirect activities against Helicobacter pylori in vitro but by themselves they are unable to cure Helicobacter pylori infection. Studies investigating the additive effect of these agents to improve the eradication rate by conventional therapy have been tried, with equivocal results. Therapeutic approaches with dietary constituents like Zinc carnosine to cure Helicobacter pylori infection are under investigation.

We learned from a previous pilot trial that $\mathrm{Zn}$-Carnosine when used as an adjuvant will improve the response to standard triple therapy from $67.3 \%$ to $82 \%(\mathrm{p}<0.001)$. Another study had demonstrated that Bacillus clausii also improved significantly the eradication rate by sequential therapy from $67.3 \%$ to $90.3 \%$, $\mathrm{p}<0.001$. In this study, we followed a modified sequential regimen of eradication applied in two different protocols and added two adjuvants to enhance the response. The basic modification in the sequential therapy was extension of the use of Amoxicillin for the whole ten days of treatment rather than using it in the first 5 days only, hence phase II of treatment would be a concomitant quadruple therapy. The treatment was further optimized by the choice of lansoprazole as a proton pump inhibitor, for its alleged bactericidal effects on helicobacter pylori and replacement of metronidazole with Tinidazolebecause in our area metronidazole resistance is very high. Clarithromycin was the third antibiotic used in group A, optimization of clarithromycin treatment was achieved by adopting the sequential regimen of treatment. It was noted earlier by Vaira et al. [9] that clarithromycin resistant strains will respond to the treatment when given sequentially. We noticed a similar observation in patients treated in our area where clarithromycin resistance is considerably high [46]. Levofloxacin was the third antibiotic used in group B. Our earlier work had indicated that replacing clarithromycin with levofloxacin in the standard triple therapy had improved the eradication rate from $69 \%$ to $84 \%$. The resistance to levofloxacin was not studied in our area. There is no consensus on the dose of levofloxacin to be used. In this regimen of therapy we increased the levofloxacin to $500 \mathrm{mg}$ twice daily for the 5 days of phase II therapy. The medicine was well tolerated in this regimen without any remarkable side effects reported, we believe this tolerance of the dose to be related to the concomitant use of probiotics and Zinc carnosine.

The probiotic used in this regimen was Bacillus clausii, chosen for the benefits we observed when added as adjuvant to sequential therapy and for its documented effects on improving the general health of the patients and reducing the side effects of the antibiotics used $[44,45]$. The dietary supplement $\mathrm{Zn}$ Carnosine had also added 
to the positive response of this regimen being a mucosal protector and by having a synergistic bactericidal effect on Helicobacter pylori.

\section{Conclusion}

This regimen of eradication that we are suggesting had yielded very promising results in the management of Helicobacter pyloriinfection, with a successful per protocol cure rate of $96.4 \%$ for the levofloxacin based and $93.4 \%$ for the clarithromycin based treatments. The response was not significantly affected by previous exposure to the antibiotics used. Patient satisfaction and compliance were remarkable with most patients having a significant feeling of wellbeing and improvement of their symptoms. The side effects to the components of the regimen were unremarkable. We believe that this systemis an optimized way of treatment by adopting the sequential setup of management and by virtue of using the most suitable antibiotics amoxicillin, clarithromycinor levofloxacin and tinidazolereplacing metronidazole. The probiotic bacillus clausii had improved the response by reducing the side effects of the antibiotics thus rendering compliance much appreciable and probably by adding to the bactericidal effect of the antibiotics through the bacteriocins they produce. The dietary supplement zinc carnosine contributed to patient satisfaction and improvement of the symptoms by enhancing healing of the mucosa and may probably add to the bactericidal effect of other components.

\section{References}

1. Marshall BJ, Warren JR (1984) Unidentified curved bacilli in the stomach of patients with gastritis and peptic ulceration. Lancet 1(8390): 1311-1315.

2. Eurogast Study Group (1993) An international association between Helicobacter pylori infection and gastric cancer. Lancet 341(8857): 1359-1362.

3. Dajani AI, Awad S, Ukabam S, Nounou MA, Abdul Rasheed Z, et al. (1999) One-week triple regime therapy consisting of pantoprazole, amoxicillin and clarithromycin for cure of Helicobacter pylori-associated upper gastrointestinal diseases. Digestion 60(3): 298-30.

4. Lind T, Velduzyen Van Zanten SJO, Unge P, Spiller R, Bayerdörffer E, et al. (1996) Eradication of Helicobacter pylori using one week triple therapies combining omeprazole, with two antimicrobials: The MACH 1 study. Helicobacter 1(3): 138-144.

5. Labenz J, Peitz U, Tillenburg B, Becker T, Börsch G, et al. (1995) Short term triple therapy with pantoprazole, clarithromycin and Metronidazole for eradication of Helicobacter pylori. LeberMagenDarm Darm 25(3): 122-127.

6. Malfertheiner P, Megraud F, O'Morain C, Bazzoli F, El-Omar E, et al. (2007) Current concepts in the management of Helicobacter pylori infection: the Maastricht III Consensus Report. Gut 56(6): 772-781.

7. Chuah SK, Hsu PI, Chang KC, Chiu YC, Wu KL, et al. (2012) Randomized comparison of two non-bismuth-containing second-line rescue therapies for Helicobacter pylori. Helicobacter 17(3): 216-223.

8. Saad RJ, Schoenfeld P, Kim HM, CheyWD (2006) Levofloxacin based triple therapy versus bismuth based quadruple therapy for persistent Helicobacter pylori infection: a meta-analysis. Am J Gastroenterol 101(3): 488-496.
9. Dino V, Angelo Z, NimishV, Luigi G, Chiara R, et al. (2007) Sequential therapy versus standard triple-drug therapy for Helicobacter pylori eradication: A randomized trial. Ann Intern Med 146(8): 556-563.

10. Liou JM, Chen CC, Chen MJ, Chen CC, Chang CY, et al. (2013) Sequential versus triple therapy for the first-line treatment of Helicobacter pylori: a multicentre, open-label, randomised trial. Lancet 381(9862): 205213.

11. Zullo A, Rinaldi V, Winn S, Meddi P, Lionetti R, et al. (2000) A new highly effective short-term therapy schedule for Helicobacter pylori eradication. Aliment Pharmacol Ther 14(6): 715-718.

12. Francavilla R, Lionetti E, Castellaneta SP, Magistà AM, Boscarelli G, et al. (2005) improved efficacy of 10-day sequential treatment for Helicobacter pylori eradication in children: A randomized trial. Gastroenterology 129(5): 1414-1419.

13. Zullo A, De Francesco V, Hassan, Morini S, Vaira D, et al. (2007) The sequential therapy regimen for Helicobacter pylori eradication: A pooled-data análisis. Gut 56(10): 1353-1357.

14. Wada T, Aiba Y, Shimizu K, Takagi A, Miwa T, et al. (1999) the therapeutic effect of bovine lactoferrin in the host infected with Helicobacter pylori. Scand J Gastroenterol 34(3): 238-243.

15. Handa O, Yoshida N, Tanaka Y, Ueda M, Ishikawa T, et al. (2002) Inhibitory effect of polaprezinc on the inflammatory response to Helicobacter pylori. Can J Gastroenterol 16(11): 785-789.

16. Kashimura H, Suzuki K, Hassan M, Ikezawa K, Sawahata T, et al. (1999) Polaprezinc, a mucosal protective agent, in combination with lansoprazole, amoxicillin, and clarithromycin increases the cure rate of Helicobacter pylori infection. Aliment PharmacolTher 13(4): 483-487.

17. Wilhelm SM, Johnson JL, Kale-Pradhan PB (2011) Treating bugs with bugs: the role of probiotics as adjunctive therapy for Helicobacter pylori. Ann Pharmacother 45(7-8): 960-966.

18. Myllyluoma E, Ahonen AM, Korpela R, Vapaatalo H, Kankuri E, et al. (2008) Effects of Multispecies Probiotic Combination on Helicobacter pylori Infection In Vitro. Clin Vaccine Immunol 15(9): 1472-1482.

19. Tong JL, Ran ZH, Shen J, Zhang CX, Xiao SD, et al. (2007) Meta-analysis: the effect of supplementation with probiotics on eradication rates and adverse events during Helicobacter pylori eradication therapy. Aliment Pharmacol Ther 25(2): 155-168.

20. Dajani AI, Abu Hammour AM, Yang DH, Chung PC, Nounou MA, et al. (2013) Do Probiotics Improve Eradication Response to Helicobacter pylori on Standard Triple or Sequential Therapy?. The Saudi Journal of Gastroenterology 19(3): 113-120.

21. Urdaci, MC, Bressollier P, Pinchuk I (2004) Bacillus clausii Probiotic Strains: Antimicrobial and Immunomodulatory Activities. J Clin Gastroenterol 38(6 suppl): S86-S90.

22. Nista EC, Candelli M, Cremonini F, Cazzato IA, Zocco MA, et al. (2004) Bacillus clausii therapy to reduce side-effects of anti-Helicobacter pylori treatment: randomized, double-blind, placebo controlled trial. Aliment PharmacolTher 20(10): 1181-1188.

23. Szajewska H, Horvath A, Piwowarczyk A (2010) Meta-analysis: the effects of Saccharomyces boulardii supplementation on Helicobacter pylori eradication rates and side effects during treatment .Aliment PharmacolTher 32(9): 1069-1079.

24. Atsushi U, Kazuo T, Yuji A, Tadahiko S, Atsushi T, et al. (2003) Lactobacillus gasseri OLL2716 as a probiotic in clarithromycinresistant Helicobacter pylori infection. Journal of Gastroenterology and Hepatology 18(8): 986-991.

25. Taylor DN, Blaser MJ (1991) the epidemiology of Helicobacter pylori infections. Epidemiol Rev 13: 42-59. 
26. Pounder RE, Ng D (1995) the prevalence of Helicobacter pylori in different countries. Aliment Pharmacol Ther 9(suppl2): 33-39.

27. Genta RM (2002) after gastritis-an imaginary journey into a Helicobacter-free world. Aliment Pharmacol Ther 16(suppl 4): 89-94.

28. Goodman KJ, Correa P (2000) Transmission of Helicobacter pylori among siblings. Lancet 355(9201): 358-362.

29. Blaser MJ, Atherton JC (2004) Helicobacter pylori persistence: biology and disease. J Clin Invest 113(3): 321-333.

30. Kusters JG, van Vliet AHM, Kuipers EJ (2006) Pathogenesis of Helicobacter pylori infection. ClinMicrobiol Rev 19(3): 449-490.

31. NimishVakil N, Megraud F (2007) Eradication Therapy for Helicobacter pylori. Gastroenterology 133(3): 985-1001.

32. Gerrits MM, Godoy APO, Kuipers EJ, Ribeiro ML, Stoof J, et al. (2006) Multiple mutations in or adjacent to the conserved penicillin-binding protein motifs of the penicillin-binding protein $1 \mathrm{~A}$ confer amoxicillin resistance to Helicobacter pylori. Helicobacter 11(3): 181-187.

33. Chen S, Li Y, Yu C (2008) Oligonucleotide microarray: a new rapid method for screening the 23S rRNA gene of Helicobacter pylori for single nucleotide polymorphisms associated with clarithromycin resistance. J Gastroenterol Hepatol 23(1): 126-131.

34. Hirata K, Suzuki H, Nishizawa T, Tsugawa H, Muraoka H, et al.(2010) Contribution of efflux pumps to clarithromycin resistance in Helicobacter pylori. Journal of Gastroenterology and Hepatology 25(1suppl): S75-S79.

35. Webber MA, Piddock LJ (2003) The importance of efflux pumps in bacterial antibiotic resistance. J Antimicrob Chemother 51(1): 9-11.

36. Wong WM, Gu Q, Lam SK, Fung FM, Lai KC, et al. (2003) Randomized controlled study of rabeprazole, levofloxacin, and rifabutin triple therapy vs. quadruple therapy as second-line treatment for Helicobacter pylori infection. Aliment Pharmacol Ther 17(4): 553-560.

37. Yee YK, Cheung TK, Chu KM, Chan CK, Fung J, et al. (2007) Levofloxacinbased quadruple therapy was inferior to traditional quadruple therapy in the treatment of resistant Helicobacter pylori infection. Aliment Pharmacol Ther 26(7): 1063-1067.
38. Wong WM, Gu Q, Chu KM, Yee YK, Fung FM, et al. (2006) Lansoprazole, levofloxacin, and amoxicillin triple therapy vs. quadruple therapy as second-line treatment of resistant Helicobacter pylori infection. Aliment Pharmacol Ther 23(3): 421-427.

39. Saad RJ, Schoenfeld P, Kim HM, Chey WD (2006) Levofloxacin-based triple therapy versus bismuth-based quadruple therapy for persistent Helicobacter pylori infection: a meta-analysis. Am J Gastroenterol 101(3): 488-496.

40. Carothers JJ, Bruce MG, Hennessy TW, Michael Bensler, Morris JM, et al. (2007) the relationship between previous fluoroquinolone use and levofloxacin resistance in Helicobacter pylori infection. Clin Infect Dis 44(2): e5-8.

41. Wheeldon TU, Granström M, Hoang TTH (2004) the importance of the level of metronidazole resistance for the success of Helicobacter pylori infection. Aliment Phamarcol Ther 19(12): 1315-1321.

42. Tong JL, Ran ZH, Shen J, Zhang CX, Xiao SD, et al. (2007) Meta-analysis: the effect of supplementation with probiotics on eradication rates and adverse events during Helicobacter pylori eradication therapy. Aliment Pharmacol Ther 25(2): 155-168.

43. Guarner F, Khan AG, Garisch J, Rami Eliakim, Gangl A, et al. (2008) World Gastroenterology Organisation Practice Guideline on Probiotics and prebiotics.

44. Nista EC, Candelli M, Cremonini F, Cazzato IA, Zocco MA, et al. (2004) Bacillus clausii therapy to reduce side-effects of anti-Helicobacter pylori treatment: randomized, double-blind, placebo controlled trial. Aliment PharmacolTher 20(10): 1181-1188.

45. Cremonini F, Di Caro S, Covino M, Armuzzi A, Gabrielli M, et al. (2002) Effect of different probiotic preparations on anti-Helicobacter pylori therapy-related side effects: a parallel group, triple blind, placebocontrolled study. Am J Gastroenterol 97(11): 2744-2749.

46. Abuhammour A, Dajani A, Nounou M, Zakaria M (2016) Standard triple therapy versus sequential therapy for eradication of Helicobacter pylori in treatment naïve and retreat patients. Arab Journal of Gastroenterology 17(3): 131-136.

\section{Your next submission with Juniper Publishers will reach you the below assets}

- Quality Editorial service

- Swift Peer Review

- Reprints availability

- E-prints Service

- Manuscript Podcast for convenient understanding

- Global attainment for your research

- Manuscript accessibility in different formats

( Pdf, E-pub, Full Text, Audio)

- Unceasing customer service

Track the below URL for one-step submission https://juniperpublishers.com/online-submission.php 